\title{
MEASURING SUSTAINABILITY IN AGRICULTURAL SYSTEMS
}

\author{
S.D. WRATTEN, M. HOFMANS*, S. THOMSEN, P. WILLIAMS 3 , \\ G. GROVES, C. EASON ${ }^{2}$ and J. GREER ${ }^{1}$
}

\author{
Department of Entomology and Animal Ecology, PO Box 84, \\ Lincoln University, Canterbury, New Zealand \\ ${ }^{1}$ Agriculture New Zealand Ltd, 295 Blenheim Road, Christchurch, New Zealand \\ ${ }^{2}$ Landcare Research New Zealand Ltd, PO Box 69, Lincoln, \\ Canterbury, New Zealand \\ ${ }^{3}$ Crop and Food Research, Private Bag 4704, Christchurch \\ *Present address: Ashburton District Council, P.O. Box 94, \\ Canterbury, New Zealand
}

\begin{abstract}
Sustainability is often discussed but rarely defined and even more rarely measured. In the farming context, a useful working definition may be borrowed from physicians' Hippocratic oath: 'First, do no harm'. However, as agriculture has harmed ecosystems, perhaps 'Identify and rectify harm' should be added to the definition. In practice in New Zealand, projects which are attempting to measure sustainability, or the lack of it, have begun. Biological, physio-chemical, biochemical and social aspects are all involved in the new 'Selwyn Stewardship Monitoring Scheme' in Canterbury. These indicators include a suite of invertebrate species, two bird species, (skylark and starling), soil organic carbon and aggregate stability, nutrient leaching, 'energy audits', biochemical markers of sublethal effects, and productivity, among others. The way these indicators are used, interpreted and the extent to which they are accepted by the farmers involved is outlined.
\end{abstract}

Keywords: sustainability, measurement, pesticide, ecosystem

\section{BACKGROUND}

Agriculture worldwide is under scrutiny because of the potential conflict between profitability, high yields and environmental integrity. The initial creation of farmland obviously removes habitats and components of biodiversity, but subsequent farming practices themselves are often inimical to populations and communities of native plants, invertebrates, birds and mammals, as well as to physical components of the farming system, such as soil structure, soil organic carbon etc. These aspects are well researched internationally (e.g. Firbanket al. 1991) but often only one practice, such as pesticide use, is investigated in terms of its impact on one species or guild of animals (see Jepson 1989). Also, many studies of the consequences of intensive agriculture concern only one 'sector', usually arable (Greaveset al. 1988; Greig-Smithet al. 1992). Rarely is a multisector, multi-disciplinary approach taken in the study of the sustainability of farming; even when it is, the work needs to extend beyond monitoring to explore the causes of any declines and the extent to which these correlate with 'concerns'. Examples of the latter are the relationship, if any, between crop productivity and earthworm populations, or that between pest populations and the numbers of predatory and parasitic invertebrates. These relationships are rarely established in agro-ecology - Fig. 1 is a rare example-and in agriculture generally; in the ecological literature, they are also relatively hard to find. These relationships are needed by land managers, conservationists and regulatory bodies to help create and implement policy. In New Zealand, for example, Regional and District Councils can interpret, and sometimes police aspects of the Resource Management Act 


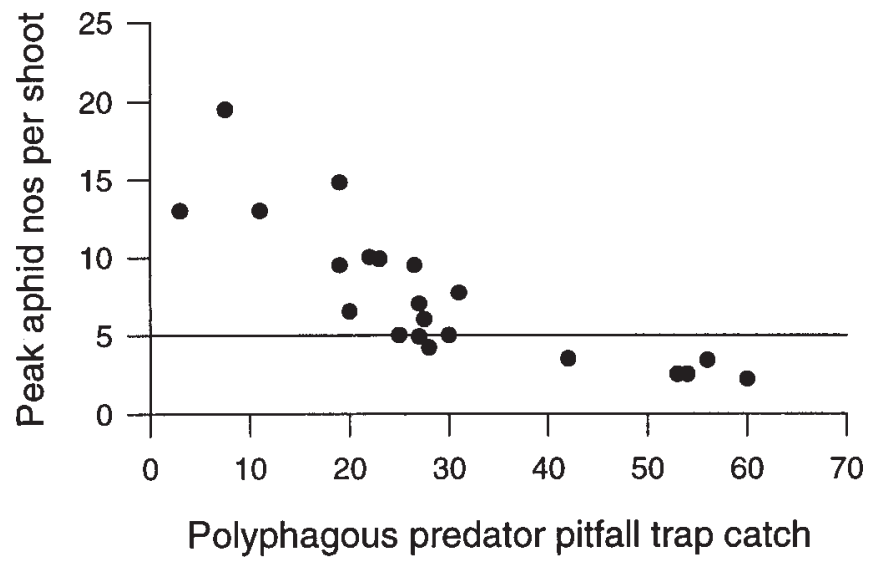

FIGURE 1: The relationship between pest number and predator number in cereals. The horizontal line is the economic threshold. (From Wratten and Powell 1991.)

on farmland, but only when potential problems are obvious, such as overt cases of water contamination from a point source. In terms of any long-term declines in aspects of farm sustainability, what and how to monitor and what the results mean, are hardly being addressed in New Zealand farming. Councils are using 'environmental consultants' because of the lack of trained personnel on their own staff, but these consultants do not necessarily have the training or experience to know what to measure. Even the establishment of a decline is not enough - a concept of an 'action threshold' needs to be developed, akin to that in insect pest management in which numbers reach a level where pesticide use is indicated (Dent 1991). An example from soil science is that shown in Fig. 2. Loss of organic matter is a 'concern' in arable agriculture worldwide but Fig. 2. reveals how, for a dryland site in Canada, there is no loss in yield until a threshold of two per cent is reached. In a natural ecosystem, Hobbs (1992) demonstrated a threshold in the

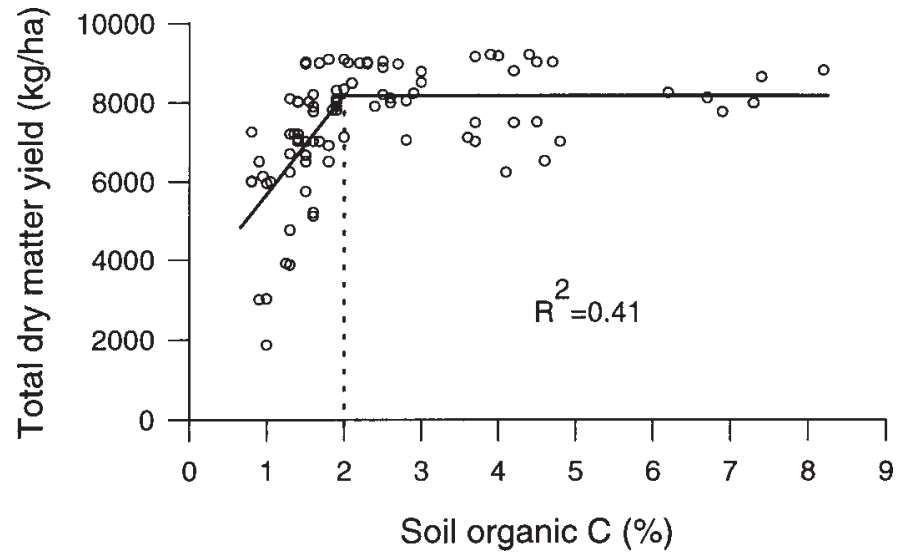

FIGURE 2: The relationship between wheat yield and soil organic carbon at one site in Alberta, Canada. (From Janzen et al. 1992). 
relationship between rate of litter decomposition and the number of species of invertebrate decomposers (Fig. 3). One of the challenges to the agro-ecologist investigating sustainability is to establish relationships such as those in Figs. 1-3. This point was made by Tokeshi (1993) in relation to natural ecosystems: 'While analysis of species abundance patterns can in theory be done with any community, its application in the context of environmental assessment is meaningful only when it is known a priori that discernible changes in species abundance patterns are associated with some kind of environmental degradation.' One reason why these relationships are rare is that the causes of changes in the dependent variable are likely to be multivariate. However, even if such relationships between a process and an agent are established and acted on in terms of changed farm practice, there

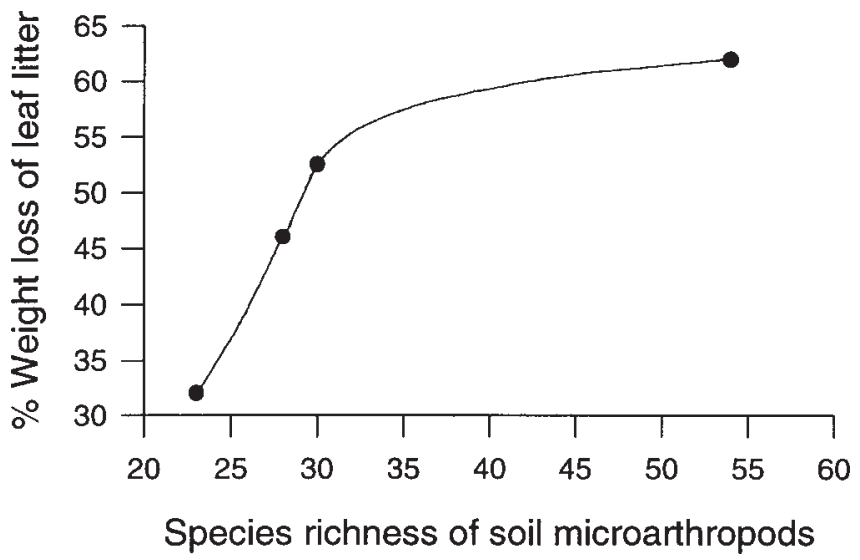

\section{FIGURE 3: The relationship between leaf-litter weight loss and litter-fauna} species richness. (From Hobbs 1992).

may be other changes in the farming environment which are considered to be undesirable, even if these are unrelated, at least in the short term, to productivity or profit. The farming landscape and its fauna and flora are an important part of many cultures, so declines in 'icon' species such as the skylark (Alauda arvensis) in Britain, a bird mentioned in Wordsworth's poems and Shakespeare's sonnets, lead to concerns which are unrelated to profit. Recent information from the United Kingdom, for instance, has shown that populations of eleven species of previously-common farmland birds, including the skylark, have declined markedly in the past decade or so. One of these, the grey partridge (Perdixperdix) has been the subject of a long-term monitoring study since the late 1960s (Potts 1986), while another, the tree sparrow (Passer montanus) has shown the greatest decline $(93 \%)$ of the group of eleven species. A long-term study of intensive cereal production in the 1980s and 1990s (Greig-Smithet al. 1992) had the prescience to select the latter species for detailed study of the effects of aphicides, used in wheat, on this species' diet and on its blood cholinesterase enzyme activity (Hartet al. 1992). The birds' diet switched to (presumably insecticide-contaminated) aphids immediately after the spraying of the aphicide and nestling esterase activity levels were lowered. Whether this led to population declines could not be demonstrated, but the general conclusion of the recent U.K. work is that 'pesticides' are responsible for the declines in the above eleven bird species. It is likely that herbicides, in particular, are most heavily implicated in these declines; the birds feed at least partly on invertebrates and populations of these are lower following the use of broad-spectrum herbicides in cereals (Sotherton 1991).

\section{THE SELWYN STEWARDSHIP MONITORING SCHEME}

The New Zealand work on farmland sustainability, described below, has tried to address some of the limitations of other related studies, may of which (in Europe) were 
reviewed by Holland et al.(1994). The 'Selwyn Stewardship Monitoring Scheme (SSMS)' is multi-sectoral and multi-disciplinary and is monitoring long-term changes in biological and physical aspects of sustainability. It is attempting to explain the multivariate causes of these changes and is seeking thresholds in these relationships (see above).

The first data for the Selwyn Scheme were collected in late 1995, using a 'pilot' set of indicators. The aim of that early work was to select indicators for their usefulness in terms of: ease of sampling, known ecological role in the agroecosystem, responsiveness

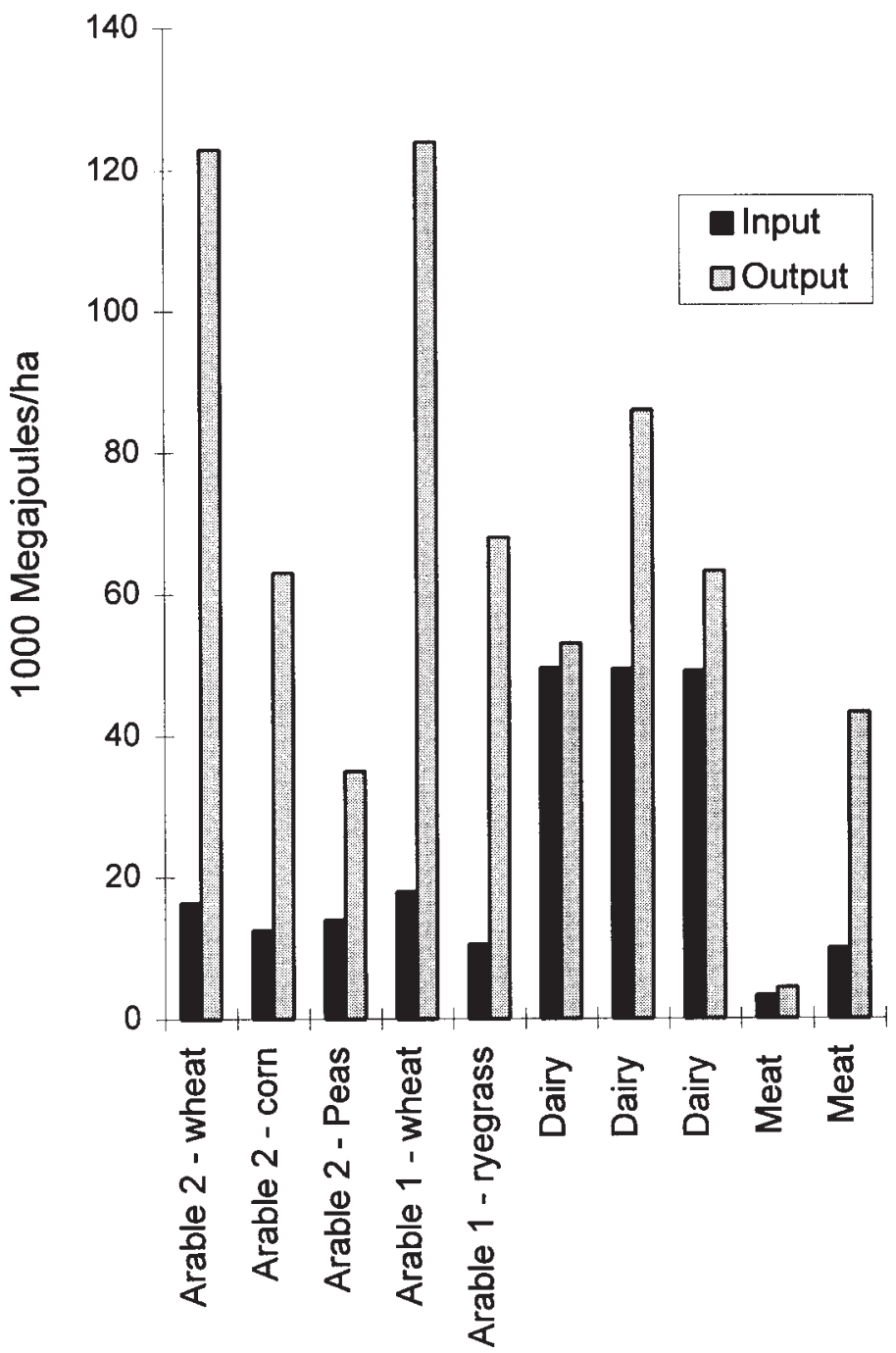

FIGURE 4: 'Energy audits' for ten paddocks in the 'Selwyn' Scheme. 
to 'perturbations' e.g., agrichemical use, cultivation etc. and relevance to 'concerns', such as soil quality, pest outbreaks, etc. There are five monitor farms (two arable, one sheep-and-beef, one dairy and one organic-registered under BioGro (Anon. 1994), and three paddocks are monitored on each farm. The current suite of invertebrate biological indicators, still subject to some review as the Scheme enters its second phase in July 1997 , is: springtails (Collembola), fungus gnats (Mycetophilidae), Argentine stem weevils (Listronotus bonariensis), brown lacewings (Microtonus tasmaniae), money spiders (Linyphiidae), predatory beetles (Carabidae), ants (Formicoidea) and earthworms (Annelida), among others. Two bird species are also being monitored. One is the skylark, chosen because of its European decline and because singing males can be easily flushed and counted, and the starling (Sturnus vulgaris). Nest boxes for the latter have been put up on all the study farms, and blood esterase levels and other biomarkers will be measured, as was done for the tree sparrow in the U.K. (see above). Other indicators include 'energy audits', which track (in megajoules/ha) the quantity of energy used for each crop or animal product and the energy 'harvested' for that crop. These data reveal the arable farm to be the most energy-efficient (Fig. 4), with meat and dairy farms considerably less so. Other indicators not reported here include: 'nutrient audits', yields, profits, soil aggregate stability, aquatic invertebrates, faecal coliform counts in, and pesticide contamination of streams, etc.

Early results are illustrated in Figs. 4 and 5 . Consistent differences between paddocks appear to persist through time, but analysis of the proportion of the variance explained by between-paddock and between-farm factors showed that the former was usually more important than the latter. For this reason, the project will reduce the number of monitor paddocks on its study farms and take on more from other farms.

It is not known at this stage whether the farms which are the most benign in environmental terms will be the most profitable or productive, or whether sustainability of the indicators will be a necessary casualty of maintaining profitability. There is a large literature on the relationships between economic growth, development and sustainability and it is by no means certain at this stage that the 'environment' must be sacrificed to profitable farming (e.g. Arrowet al. 1995). In the context of the Selwyn Scheme, the next year or so will be crucial in beginning to answer that question, and in achieving the goal of relating indicator levels to significant environmental changes in farmland. To quote

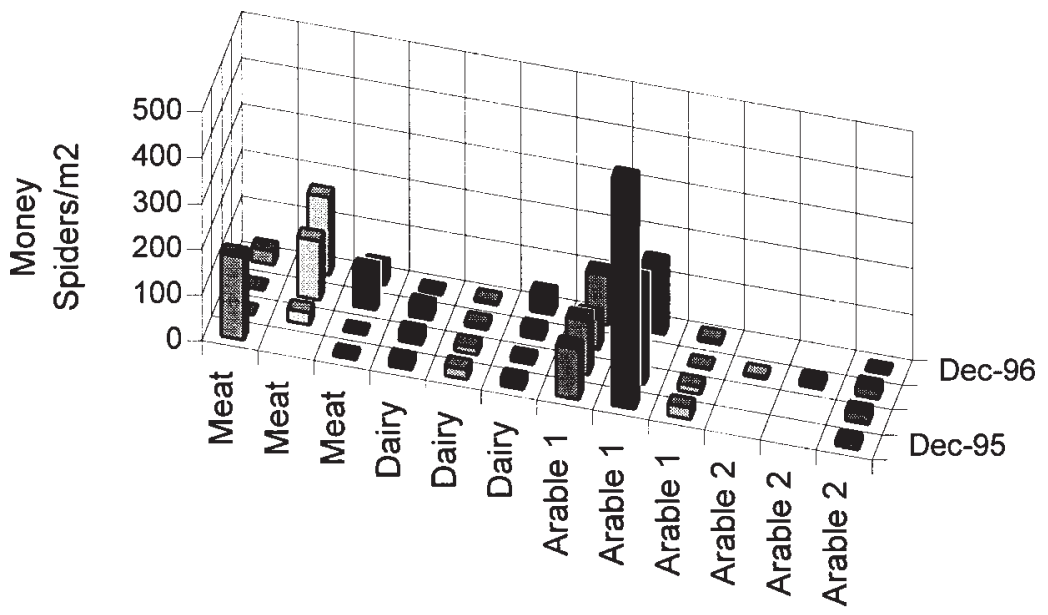

FIGURE 5: Moneyspider(Linyphiidae) numbers on four dates in twelve paddocks in the 'Selwyn' Scheme. 
Potts (1991), who wrote in a Preface to Firbank et al. 1991: 'The policies and practices which had done so much to improve the productivity of food were being questioned over their emphasis on quantity rather than quality-of produce, of environment, of life' - a statement applicable to New Zealand in 1997 ?

\section{REFERENCES}

Anon., 1994. Certified Bio-Gro Organic Production Standards. N.Z. Biological Producers and Consumers Council Inc.

Arrow, K., Bolin, B, Constanza, R., Dasgupta, P. Folke, C., Holling, C.S., Jansson, BO., Levin, S., Mäler, K-G., Perrings, C. and Pimentel, D., 1995. Economic growth, carrying capacity and the environment. Ecol. Econ. 15:91-95.

Firbank, L.G., Carter, N., Darbyshire, J.F. and Potts, G.R., 1991. The Ecology of Temperate Cereal Fields. 32nd Symposium of the British Ecological Society. Blackwell Scientific Publications, 469 pp.

Greaves, M.P., Smith, B.D. and Greig-Smith, P.W., 1988. (Eds.). Field Methods for the Study of Environmental Effects of Pesticides. British Crop Protection Council Monograph No. 40. British Crop Protection Council, Thornton Heath. 370 pp.

Greig-Smith, P.W., Frampton, G.K. and Hardy, A.R., 1992. (Eds.). Pesticides, Cereal Farming and the Environment. HMSO, London. 288 pp.

Hart, A.D.M., Thompson, H.M., Fletcher, M.R., Greig-Smith, P.W., Hardy, A.R. and Langton, S.D., 1992. Exposure of tree sparrows to summer aphicides. Pp. 175-193. In: Cereal Farming, Pesticides and the Environment. P.W. Greig-Smith, G.K. Frampton and A.R. Hardy (Eds.). HMSO, London.

Hobbs, R.J., 1992. Is biodiversity important for ecosystem functioning? Implications for research and management. Pp. 211-229. In: Biodiversity of Mediterranean Ecosystems in Australia. R.J. Hobbs (Ed.). Surrey Beaty.

Holland, J.M., Frampton, G.K., Çilgi, T. and Wratten, S.D., 1994. Arable acronyms analysed - a review of integrated arable farming systems in Western Europe-Annals Appl. Biol. 125: 399-438.

Janzen, H.H., Larney, F.J. and Olsen, B.M., 1992. Soil quality factors of problem soils in Alberta. Proceedings of the Alberta Soil Science Workshop, Alberta, Canada.

Jepson, P.C., 1989. (Ed.). Pesticides and Non-target Invertebrates. Intercept, Wimborne, Dorset. 240 pp.

Potts, G.R., 1986. The Partridge: Pesticides, Predation and Conservation. Collins, London.

Potts, G.W., 1991. Preface. Pp. 233-257.In: Ecology of Temperate Cereal Fields. L.G. Firbank, N. Carter, J.F. Darbyshire and G.R. Potts (Eds.).

Tokeshi, M., 1993. Species abundance patterns and community structure.Advances in Ecological Res. 24: 111-186.

Wratten, S.D. and Powell, W., 1991. Cereal aphids and their natural enemies. Pp. 233257.In: Ecology of Temperate Cereal Fields. L.G. Firbank, N. Carter, J.F. Darbyshire and G.R. Potts (Eds.) 